\title{
Nanotechnology and its use in imaging and drug delivery (Review)
}

\author{
SERJAY SIM and NYET KUI WONG \\ School of Health Sciences, Division of Applied Biomedical Sciences and Biotechnology, \\ International Medical University, Kuala Lumpur 57000, Malaysia \\ Received January 21, 2019; Accepted February 9, 2021
}

DOI: $10.3892 /$ br.2021.1418

\begin{abstract}
Nanotechnology is the exploitation of the unique properties of materials at the nanoscale. Nanotechnology has gained popularity in several industries, as it offers better built and smarter products. The application of nanotechnology in medicine and healthcare is referred to as nanomedicine, and it has been used to combat some of the most common diseases, including cardiovascular diseases and cancer. The present review provides an overview of the recent advances of nanotechnology in the aspects of imaging and drug delivery.
\end{abstract}

\section{Contents}

1. Introduction

2. Nanotechnology in medicine and healthcare

3. Types of nanoparticles

4. Nanotechnology in imaging and diagnosis

5. Nanotechnology and cancer treatment

6. Nanotechnologies for the treatment of cardiovascular diseases

7. Potential risks of nanotechnologies

8. Conclusion

\section{Introduction}

Nanoscience is the study of the unique properties of materials between 1-100 nm, and nanotechnology is the application of such research to create or modify novel objects. The ability to manipulate structures at the atomic scale allows for the creation of nanomaterials (1-3). Nanomaterials have unique optical, electrical and/or magnetic properties at the nanoscale, and these can be used in the fields of electronics and medicine, amongst other scenarios. Nanomaterials are unique as they provide a large surface area to volume ratio. Unlike other

Correspondence to: Professor Nyet Kui Wong, School of Health Sciences, Division of Applied Biomedical Sciences and Biotechnology, International Medical University, 126 Jalan Jalil Perkasa 19, Kuala Lumpur 57000, Malaysia

E-mail: wongnyetkui@imu.edu.my

Key words: nanotechnology, nanomedicine, imaging, drug delivery system, health concerns large-scaled engineered objects and systems, nanomaterials are governed by the laws of quantum mechanics instead of the classical laws of physics and chemistry. In short, nanotechnology is the engineering of useful objects and functional systems at the molecular or atomic scale (4).

Nanotechnologies have had a significant impact in almost all industries and areas of society as it offers i) better built, ii) safer and cleaner, iii) longer-lasting and iv) smarter products for medicine, communications, everyday life, agriculture and other industries (5). The use of nanomaterials in everyday products can be generally divided into two types. First, nanomaterials can be merged or added to a pre-existing product and improve the composite objects' overall performance by lending some of its unique properties. Otherwise, nanomaterials such as nanocrystals and nanoparticles can be used directly to create advanced and powerful devices attributed to their distinctive properties. The benefits of nanomaterials could potentially affect the future of nearly all industrial sectors (6).

The beneficial use of nanomaterials can be found in sunscreens, cosmetics, sporting goods, tyres, electronics and several other everyday items (6). Additionally, nanotechnologies have revolutionized advances in medicine, specifically in diagnostic methods, imaging and drug delivery. Table I illustrates the areas where nanotechnologies have had a significant impact.

Nanomaterials allow mass-creation of products with enhanced functionality, significantly lower costs, and greener and cleaner manufacturing processes, to improve healthcare and reduce the impact of manufacturing on the environment (7).

\section{Nanotechnology in medicine and healthcare}

Nanomedicine is the term used to refer to the applications of nanotechnologies in medicine and healthcare. Specifically, nanomedicine uses technologies at the nanoscale and nano-enabled techniques to prevent, diagnose, monitor and treat diseases (8). Nanotechnologies exhibit significant potential in the field of medicine, including in imaging techniques and diagnostic tools, drug delivery systems, tissue-engineered constructs, implants and pharmaceutical therapeutics (9), and has advanced treatments of several diseases, including cardiovascular diseases, cancer, musculoskeletal conditions, psychiatric and neurodegenerative diseases, bacterial and viral infections, and diabetes (10). 


\section{Types of nanoparticles}

To date, several nanoparticles and nanomaterials have been investigated and approved for clinical use. Some common types of nanoparticles are discussed below.

Micelles. Micelles are amphiphilic surfactant molecules that consist of lipids and amphiphilic molecules. Micelles spontaneously aggregate and self-assemble into spherical vesicles under aqueous conditions with a hydrophilic outer monolayer and a hydrophobic core, and thus can be used to incorporate hydrophobic therapeutic agents. The unique properties of micelles allow for the enhancement of the solubility of hydrophobic drugs, thus improving bioavailability. The diameter of micelles ranges from 10-100 $\mathrm{nm}$. Micelles have various applications, such as drug delivery agents, imaging agents, contrast agents and therapeutic agents (11).

Liposomes. Liposomes are spherical vesicles with particle sizes ranging from $30 \mathrm{~nm}$ to several microns, that consist of lipid bilayers. Liposomes can be used to incorporate hydrophilic therapeutic agents inside the aqueous phase and hydrophobic agents in the liposomal membrane layer. Liposomes are versatile; their surface characteristics can be modified with polymers, antibodies and/or proteins, enabling macromolecular drugs, including nucleic acids and crystalline metals, to be integrated into liposomes $(10,11)$. Poly(ethylene glycol) (PEG)ylated liposomal doxorubicin $\left(\right.$ Doxil $\left.^{\circledR}\right)$ is the first FDA-approved nanomedicine, which has been used for treatment of breast cancer, and it enhances the effective drug concentration in malignant effusions without the need to increase the overall dose $(10,11)$.

Dendrimers. Dendrimers are macromolecules with branched repeating units expanding from a central core and consists of exterior functional groups (10-12). These functional groups can be anionic, neutral or cationic terminals, and they can be used to modify the entire structure, and/or the chemical and physical properties. Therapeutic agents can be encapsulated within the interior space of dendrimers, or attached to the surface groups, making dendrimers highly bioavailable and biodegradable. Conjugates of dendrimers with saccharides or peptides have been shown to exhibit enhanced antimicrobial, antiprion and antiviral properties with improved solubility and stability upon absorption of therapeutic drugs (13). Polyamidoamine dendrimer-DNA complexes (called dendriplexes) have been investigated as gene delivery vectors and hold promise in facilitating successive gene expression, targeted drug delivery and improve drug efficacy $(14,15)$. dendrimers are promising particulate systems for biomedical applications, such as in imaging and drug delivery $(16,17)$, due to their transformable properties.

Carbon nanotubes. Carbon nanotubes are cylindrical molecules that consist of rolled-up sheets of a single-layer of carbon atoms (graphene). They can be single-walled or multi-walled, or composed of several concentrically interlinked nanotubes (17). Due to their high external surface area, carbon nanotubes can achieve considerably high loading capacities as drug carriers. Additionally, their unique optical, mechanical and electronic properties have made carbon tubes appealing as imaging contrast agents $(18,19)$ and biological sensors $(20)$.

Metallic nanoparticles. Metallic nanoparticles include iron oxide and gold nanoparticles. Iron oxide nanoparticles consist of a magnetic core (4-5 nm) and hydrophilic polymers, such as dextran or PEG (17-20). Conversely, gold nanoparticles are composed of a gold atom core surrounded by negative reactive groups on the surface that can be functionalized by adding a monolayer of surface moieties as ligands for active targeting (17-20). Metallic nanoparticles have been used as imaging contrast agents (21), in laser-based treatment (12), as optical biosensors (12) and drug delivery vehicles (22).

Quantum dots. Quantum dots (QDs) are fluorescent semiconductor nanocrystals (1-100 nm) and have shown potential use for several biomedical applications, such as drug delivery and cellular imaging $(17,23,24)$. Quantum dots possess a shell-core structure, in which the core structure is typically composed of II-VI or III-V group elements of the periodic table. Due to their distinctive optical properties and size, with high brightness and stability, quantum dots have been employed in the field of medical imaging $(10,23)$.

\section{Nanotechnology in imaging and diagnosis}

Diagnosis of a disease is one of the most crucial steps in the healthcare process. All diagnoses are desired to be quick, accurate and specific to prevent 'false negative' cases. In vivo imaging is a non-invasive technique that identifies signs or symptoms within a patient's live tissues, without the need to undergo surgery (24). A previous improvement in diagnostic imaging techniques is the use of biological markers that can detect changes in the tissues at the cellular level. The aim of using a biological marker is to detect illnesses or symptoms, thereby serving as an early detection tool (25). Notably, some of these high precision molecular imaging agents have been developed through the use of nanotechnologies. In addition to diagnosis, imaging is also vital for detecting potential toxic reactions, in controlled drug release research, evaluating drug distribution within the body and closely monitoring the progress of a therapy. Potential drug toxicity can be reduced with the possibility of monitoring the distribution of drugs around the body and by releasing the drug as required (26).

Diagnostic imaging. Imaging techniques such as X-ray, ultrasound, computed tomography, nuclear medicine and magnetic resonance imaging are well established, and are widely used in biochemical and medical research. However, these techniques can only examine changes on the tissue surface relatively late in disease progression, although they can be improved through the use of contrast and targeting agents based on nanotechnologies, to improve resolution and specificity, by indicating the diseased site at the tissue level (27). Currently used medical imaging contrast agents are primarily small molecules that exhibit fast metabolism and a non-specific distribution, and can thus potentially result in undesirable toxic side effects (10). This particular area is where nanotechnologies make their most significant contribution in the field of medicine, by developing more powerful contrast agents for 
Table I. Potential areas where nanotechnologies may have a significant impact.

\begin{tabular}{|c|c|c|}
\hline Area & Potential & Refs. \\
\hline \multirow[t]{4}{*}{ Healthcare } & Development of personalised medicine. & - \\
\hline & Precise and accurate drug delivery systems. & - \\
\hline & Robotic and automated surgical techniques. & - \\
\hline & Cochlear implants, the ability to re-join damaged nerves and use in retinal implants. & $(60,61)$ \\
\hline \multirow[t]{2}{*}{ Energy } & $\begin{array}{l}\text { More efficient use of energy through the development of smart } \\
\text { buildings that respond to the environment. }\end{array}$ & - \\
\hline & Reduce fuel consumption and cost by using stronger and lighter materials for vehicles. & $(62-63)$ \\
\hline \multirow[t]{2}{*}{ Environment } & Reduce pollution by acting as molecular sieves for capture of pollutants. & - \\
\hline & Detect pollutants in the air and water through new disposable sensors. & (64) \\
\hline
\end{tabular}

Table II. Examples of nanoparticles used as contrast agents in the biomedical field.

\begin{tabular}{ll}
\hline Nanoparticle & \multicolumn{1}{c}{ Application } \\
\hline Perfluorocarbon & Imaging of angiogenesis, cancer metastases and blood clots. \\
Gadolinium complexes & CT imaging of thrombi as a contrast agent. \\
Fullerenes & Used in MRI to enhance contrast. \\
Quantum dots & Specific cellular imaging. \\
Silicon particles & Coated with conductive layers to enhance MRI. \\
Iron oxide & Imaging of tumours. \\
Gold particles (core shell structure) & Ultrasound. \\
Gold particles & X-ray/CT scan. \\
\hline
\end{tabular}

CT, computed tomography; MRI, magnetic resonance imaging.

almost all imaging techniques, as nanomaterials exhibit lower toxicity, and enhanced permeability and retention effects in tissues. The size of the nanoparticles significantly influences its biodistribution, blood circulation half-life, cellular uptake, tissue penetration and targeting $(17,28)$. Table II summarises some examples of nanoparticles used as contrast agents in molecular imaging.

The use of nanoparticles in X-rays has some limitations. In order to enhance the contrast, a number of heavy atoms must be delivered into the target site without causing any toxic reactions. This can be achieved using stable and inert surface atoms, such as gold and silver. Hence, gold nanoshells have garnered significant attention, due to its low toxicity. Gold nanoshells are heavy metal nanoparticles (dielectric core) encapsulated in gold shells and have been proposed to be one of the most promising materials in optical imaging of cancers $(29,30)$. Gold nanoshells are cost-effective, safe due to its non-invasive property and may provide high resolution imaging. Gold nanoshells have similar physical characteristics to gold colloids, as they both possess a unified electronic response of the metal to light resulting in active optical absorption (29-32). Gold nanoshells are widely employed by researchers as contrast agents in the Optical Coherence Tomography of cancer cells, as the optical resonance of gold nanoshells can be adjusted accurately over a wide range, including near-infrared, where tissue transmissivity is higher (31). Table III shows the various types of nanomaterials used as contrast agents in pre-clinical investigations and in clinical use. Significantly more research and pre-clinical studies are required to understand and predict the effects of these nanomaterials in biological systems.

In situ diagnostic devices. In situ diagnostic devices, such as capsule endoscopy cameras, have been shown to be successful in the clinical stage. These devices can locate and image the bleeding site and other internal problems via oral ingestion. It is hypothesized that in the future, these devices will incorporate nano-scaled sensors for chemicals, virus, bacteria and $\mathrm{pH}$ to broaden their utility and applications. Moreover, these devices are also being developed as an alternative safe and precise means of drug-loaded capsules in drug delivery systems $(33,34)$.

Nanotechnology in drug delivery. Therapy typically involves delivering drugs to a specific target site. If an internal route for drug delivery is not available, external therapeutic methods, such as radiotherapy and surgical procedures are employed. These methods are often used interchangeably or in combination to combat diseases. The goal of therapy is to always selectively remove the tumours or the source of illness in a long-lasting manner (35). Nanotechnologies are making a compelling contribution in this area through the development of novel modes for drug delivery, and some of these methods have proven effective in a clinical setting and are clinically used (36). For example, doxorubicin a 
Table III. Types of nanomaterials used as contrast agents.

\begin{tabular}{|c|c|c|c|c|}
\hline Nanomaterials & Applications & Status & Remarks & Refs. \\
\hline $\begin{array}{l}\text { Gadolinium nanostructure polymers, } \\
\text { liposomes, inorganic nanoparticles }\end{array}$ & MRI imaging & Pre-clinical & - & $(32,75-80)$ \\
\hline $\begin{array}{l}\text { Superparamagnetic iron-oxide } \\
\text { nanoparticles coated with dextran }\end{array}$ & MRI imaging & $\begin{array}{l}\text { Clinical use; } \\
\text { FDA Approved } \\
\text { (Feridex/Endorem) }\end{array}$ & $\begin{array}{l}\text { Has been withdrawn } \\
\text { from market } \\
\text { due to lack of use. }\end{array}$ & $(10,81-87)$ \\
\hline $\begin{array}{l}\text { Superparamagnetic } \\
\text { Iron-Oxide Nanoparticles } \\
\text { coated with dextran }\end{array}$ & MRI imaging & $\begin{array}{l}\text { Clinical use; } \\
\text { FDA Approved } \\
\text { (GastroMark; Umirem) }\end{array}$ & $\begin{array}{l}\text { Has been withdrawn } \\
\text { from market } \\
\text { due to lack of use. }\end{array}$ & $(10,81-87)$ \\
\hline Bismuth sulphide (Bi2S3) nanoparticles & CT scan & Pre-clinical & - & (88) \\
\hline $\begin{array}{l}\text { Iodinated liposomal carriers, } \\
\text { inorganic nanostructures }\end{array}$ & CT scan & Pre-clinical & - & $(89-95)$ \\
\hline Gold particles & CT scan & Pre-clinical & - & $(96-97)$ \\
\hline Quantum Dots & $\begin{array}{l}\text { Florescence/optical } \\
\text { imaging }\end{array}$ & Pre-clinical & - & $(98-101)$ \\
\hline
\end{tabular}

CT, computed tomography; MRI, magnetic resonance imaging.

Table IV. Comparison of nanoparticles and fine particles in drug delivery systems.

\begin{tabular}{ll} 
Nanoparticles & \multicolumn{1}{c}{ Fine particles } \\
\hline $\begin{array}{l}\text { Increased bioavailability } \\
\text { Dose proportionality }\end{array}$ & $\begin{array}{l}\text { Low bioavailability } \\
\text { Potential toxic effects } \\
\text { Decreased toxicity }\end{array}$ \\
Larger and unstable \\
dosage form \\
Low agent surface area hence \\
low dissolution rate
\end{tabular}

Large agent surface area

hence high dissolution rate

drug which exhibits high toxicity, can be delivered directly to tumour cells using liposomes (Doxil ${ }^{\circledR}$ ) without affecting the heart or kidneys. Additionally, paclitaxel incorporated with polymeric mPEG-PLA micelles (Genexol-PM ${ }^{\circledR}$ ) are used in chemotherapeutic treatment of metastatic breast cancers $(10,11,36)$. The success of nanotechnologies in drug delivery can be attributed to the improved in vivo distribution, evasion of the reticuloendothelial system and the favourable pharmacokinetics (36).

A perfect drug delivery system encompasses two elements: Control over drug release and the targeting ability. Side effects can be reduced significantly, and drug efficiency can be ensured by specifically targeting and killing harmful or cancerous cells. Additionally, controlled drug release can also reduce the side effects of drugs (37). Benefits of nanoparticle drug delivery systems include minimised irritant reactions and improved penetration within the body due to their small size, allowing for intravenous and other delivery routes. The specificity of nanoparticle drug delivery systems is made possible by attaching nano-scaled radioactive antibodies that are complementary to antigens on the cancer cells with drugs, and these approaches have produced desirable results (38), exhibiting improved i) drug bioavailability, ii) delivery of drugs specifically to the target site, and iii) uptake of low solubility drugs (39). Table IV summarises the advantages of nanoparticles over conventional fine particles $(39,40)$.

\section{Nanotechnology and cancer treatment}

Staggering numbers of individuals suffer from cancer worldwide, highlighting the need for an accurate detection method and novel drug delivery system that is more specific, efficient and exhibits minimal side effects (41). Anticancer treatments are often regarded as superior if the therapeutic agent can reach the specific target site without resulting in any side effects. Chemical modifications of the surface of nanoparticle carriers may improve this required targeted delivery. One of the best examples of modifications at the surface of nanoparticles is the incorporation of PEG or polyethylene oxide. These modifications enhance not only the specificity of drug uptake, but also the tumour-targeting ability. Incorporating PEG avoids the detection of nanoparticles as foreign objects by the body's immune system, thus allowing them to circulate in the bloodstream until they reach the tumour. Additionally, the application of hydrogel in breast cancer is a prime example of this innovative technology. Herceptin is a type of monoclonal antibody used in breast cancer treatment by targeting human epidermal growth factor receptor 2 (HER2) on cancer cells. A vitamin E-based hydrogel has thus been developed that can deliver Herceptin to the target site for several weeks with just a single dose. Due to the improved retention of Herceptin within the tumour, the hydrogel-based drug delivery is more efficient than conventional subcutaneous and intravenous delivery modes, thus making it a better anti-tumour agent (42-44). Nanoparticles can be modified in several ways to prolong circulation, enhance drug localisation, increase drug efficacy and potentially decrease the development of multidrug resistance through the use of nanotechnologies. 
Table V. Examples of FDA approved nanomedicines.

\begin{tabular}{|c|c|c|}
\hline Clinical agents & Formulation & Applications \\
\hline Eligard & $\begin{array}{l}\text { Leoprolide acetate and polymer } \\
\text { [poly (DL-lactide-co-glycolide)] }\end{array}$ & Prostate cancer \\
\hline Genexol-PM & mPEG-PLA micelle loaded with paclitaxel & Metastatic breast cancer \\
\hline Doxil/Caelyx & Liposomal doxorubicin & $\begin{array}{l}\text { Ovarian, breast cancer, Kaposi's sarcoma, } \\
\text { multiple myeloma }\end{array}$ \\
\hline Myocet & Liposomal doxorubicin & $\begin{array}{l}\text { Combination therapy with cyclophosphamide } \\
\text { in metastatic breast cancer }\end{array}$ \\
\hline Onivyde & Liposomal irinotecan & Pancreatic cancer \\
\hline Cynviloq & $\begin{array}{l}\text { Paclitaxel-loaded poly(ethylene glycol)- } \\
\text { b-poly(D,L-lactic acid) block copolymers }\end{array}$ & $\begin{array}{l}\text { Non-small cell lung cancer } \\
\text { and metastatic breast cancer. }\end{array}$ \\
\hline Nanoxel & $\begin{array}{l}\text { Docetaxel-loaded poly(ethylene glycol)- } \\
\text { b-poly(D,L-lactic acid) block copolymers }\end{array}$ & $\begin{array}{l}\text { Breast cancer, non-small-cell lung } \\
\text { cancer, prostate cancer, ovarian cancer, } \\
\text { head and neck cancer, oesophageal cancer }\end{array}$ \\
\hline
\end{tabular}

There are several studies using FDA-approved nano drugs, such as Abraxane ${ }^{\circledR}$, Doxil ${ }^{\circledR}$ or Genexol-PM ${ }^{\circledR}$ as adjuvants in combinatory cancer treatment. Abraxane ${ }^{\circledR}$, a paclitaxel albumin-stabilised nanoparticle formulation (nab-paclitaxel) has been approved for the treatment of metastatic breast cancer (45). There are $>900$ ongoing clinical trials involving nab-paclitaxel as an anticancer agent, based on Clinicaltrials. gov as of August 2020. Moreover, nab-paclitaxel, in combination with 5-chloro-2.4-dihydrooxypyridine, tegafur and oteracil potassium exhibited promising results when used for the treatment of HER2-negative breast cancer patients (46). Doxorubicin, daunorubicin, paclitaxel and vincristine are among the most extensively investigated anticancer agents in liposome-based drug formulations $(10,11)$. Table V provides examples of FDA approved nanomedicines (10).

\section{Nanotechnologies for the treatment of cardiovascular diseases}

Cardiovascular diseases are another field where the properties of nanoparticles may be leveraged. Cardiovascular diseases are the leading cause of death globally, and the rates are increasing alarmingly, due to an increase in sedentary lifestyles (47). Common examples of cardiovascular diseases that affect several individuals includes stroke, hypertension and restriction or blockage of blood circulation in a specific area. These diseases are the most common causes of prolonged disability and death (47). Nanotechnologies offer novel avenues for therapeutic and diagnostic strategies for management of cardiovascular diseases.

Most cardiovascular risk factors (for example, for hypertension, smoking, hypercholesterolemia, homocystinuria and diabetes mellitus) are associated with impaired nitric oxide (NO) endothelial production. Impaired endothelial function is established to be the first step in atherosclerosis. Gold and silica nanoparticles have been developed to improve NO supply for possible application in cardiovascular diseases, where low NO bioavailability occurs (48). Systemic administration of the 17- $\beta$ E loaded CREKA-peptide-modified-nanoemulsion system has been shown to reduce the levels of pathological contributors to early atherosclerosis by reducing lesion size, lowering the levels of circulating plasma lipids and decreasing the gene expression of inflammatory markers associated with the disease (49). Moreover, novel formulations of block copolymer micelles constructed using PEG and poly(propylene sulphide) have been demonstrated to suppress the levels of pro-inflammatory cytokines (50), and exhibited excellent potential for management of atherosclerosis (50).

Drug delivery via liposomes has been proven to be effective for prevention of platelet aggregation, atherosclerosis and thrombosis. Prostaglandin E-1 (PGE-1) exhibits a wide range of pharmacological properties, including vasodilation, inhibition of platelet aggregation, leukocyte adhesion, as well as exhibiting an anti-inflammatory effect. Liposomal drug delivery of PGE-1 (Liprostin ${ }^{\mathrm{TM}}$ ), is currently undergoing phase III clinical trials for the treatment of various cardiovascular diseases, such as restenosis following angioplasty (51). Additionally, the use of liposomes carrying the thrombolytic drug urokinase has also been assessed; cyclic arginyl-glycyl-aspartic acid (cRGD) peptide liposomes encapsulated with urokinase can selectively bind to the GPIIb/IIIa receptors, and this improves the thrombolytic efficacy of urokinase by almost 4-fold over free urokinase (51).

Efficacy and effectiveness of the conventional thrombolytic drugs can also be advanced via novel nano-therapeutic approaches. Drugs can be selectively targeted to vascular blockage sites through mechanical activation within blood vessels based on the high-fluid shear strains present within them. In vivo and in vitro studies have been encouraging, thus validating this approach for use in lysis of blood clots, using a significantly lower amount of thrombolytic drug (48-53). One example of this technology is the use of dendrimers. Dendrimers have been used in several diseases as a means of delivering therapeutic agents. Plasminogen activator (rtPA) has been successfully attached to dendrimers producing an alternative drug delivery system, allowing for refinement of the rtPA-dendrimer complex concentration throughout the duration of treatment using different dilution proportions of each part of the complex (53). Another potential role of nanoparticles is to decrease haemorrhaging, which is a severe side effect of 
Table VI. Applications of nanoscale pharmaceuticals in drug delivery.

\begin{tabular}{|c|c|c|c|c|}
\hline First author, year & Nanomaterial & Properties & Applications & Refs. \\
\hline Serp et al, 2003 & $\begin{array}{l}\text { Nanoparticles in the } \\
\text { range of } 50-100 \mathrm{~nm}\end{array}$ & $\begin{array}{l}\text { Move into tumour } \\
\text { more readily. }\end{array}$ & Treatment of cancer. & $(102)$ \\
\hline Serp et al, 2003 & Polymers & High accuracy. & $\begin{array}{l}\text { Nanobiological } \\
\text { drug-carrying devices. }\end{array}$ & $(102)$ \\
\hline Ghosh et al, 2003 & $\begin{array}{l}\text { Ligands on a } \\
\text { nanoparticle surface }\end{array}$ & High accuracy. & $\begin{array}{l}\text { Ligands can recognise markers } \\
\text { on damaged tissues } \\
\text { and deliver drugs to them. }\end{array}$ & (103) \\
\hline Ghosh et al, 2003 & Nanocapsules & $\begin{array}{l}\text { Evasion of the body's } \\
\text { immune system } \\
\text { and allows targeting } \\
\text { of drugs to a specific site. }\end{array}$ & $\begin{array}{l}\text { A buckyball-based } \\
\text { treatment for AIDS has just } \\
\text { entered clinical testing. }\end{array}$ & $(103)$ \\
\hline Ghosh et al, 2003 & $\begin{array}{l}\text { Improved particle } \\
\text { adhesion }\end{array}$ & $\begin{array}{l}\text { Increased localised } \\
\text { drug retention. }\end{array}$ & Controlled drug release. & $(103)$ \\
\hline
\end{tabular}

Table VII. Potential risks of nanotechnologies.

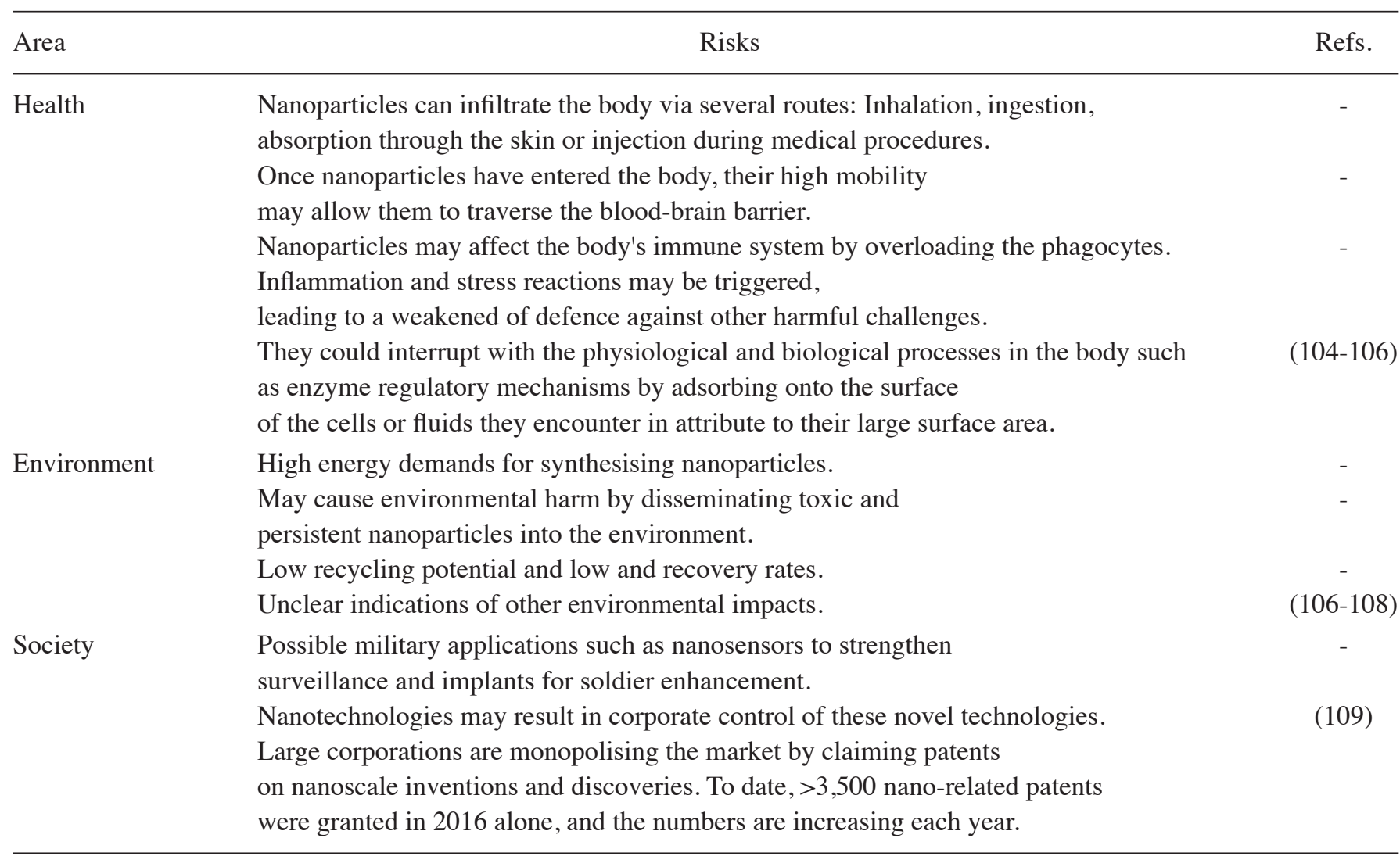

thrombolytic agents. Targeted thrombolysis via rtPA bound to polyacrylic acid coated nanoparticles minimises the intracerebral haemorrhage, and enhances retention at the target site (11).

Incorporation of nanotechnologies has assisted in reducing the side effects of drugs, whilst requiring lower doses of the drug to treat cardiovascular diseases. Table VI summarises some of the applications of nanoscale pharmaceuticals in drug delivery.

The current progress in nanotechnology research for drug delivery systems, particularly with regard to their water-insoluble properties, has enabled drugs to be delivered to target sites with higher carrier capacity, specificity and stability. The constant advancements in nanoparticle drug delivery systems have allowed researchers to develop formulations that can increase the efficiency of drugs, whilst reducing the cost (54).

\section{Potential risks of nanotechnologies}

Although the emerging field of nanotechnology has piqued the public's interest at large, nanotechnologies have also resulted in extensive discussions regarding their safety and any health 
risks associated with their use. New challenges arise with the use of nanomaterials, specifically in predicting, understanding and governing the potential health risks. Research has demonstrated that low-solubility nanoparticles are more hazardous and toxic on a mass by mass basis than larger particles (55). Other potential risks posed by nanoparticles include explosions and catalytic effects. It is important to note that only specific nanomaterials are considered risky, particularly those with high reactivity and mobility. Until more thorough studies can confirm the hazardous effects of nanomaterials, the mere presence of them in a laboratory setting will not in itself impose a threat to humanity and the environment (56). Potential risks of nanotechnology can be broadly grouped into three areas: Health, environment and society, as shown in Table VII.

\section{Conclusion}

There is no doubt that nanotechnologies have helped to improve the quality of life of patients by providing a platform for advances in biotechnological, medicinal and pharmaceutical industries. They have also facilitated healthcare procedures, from diagnosis to therapeutic interventions and follow-up monitoring. There is a constant push to create and develop novel nanomaterials to improve diagnosis and cures for diseases in a targeted, accurate, potent and long-lasting manner, with the ultimate aim of making medical practices more personalised, cheaper and safer $(57,58)$. The prospect of nanotechnology lies within using the right nanomaterials and reducing any possible harmful effects. It is important to note that, risk evaluations are required before new nano-based products are approved for clinical and commercial use, as with any other product, to minimise any potential hazards to human health and the environment. A full life cycle evaluation is required to more accurately ascertain the sustainability and safety of their use long term (59).

\section{Acknowledgements}

Not applicable.

\section{Funding}

No funding was received.

\section{Availability of data and materials}

Not applicable.

\section{Authors' contributions}

SS and NKW both wrote and revised the manuscript. Both authors have read and approved the final manuscript.

\section{Ethics approval and consent to participate}

Not applicable.

\section{Patient consent for publication}

Not applicable.

\section{Competing interests}

The authors declare that they have no competing interests.

\section{References}

1. Drexler KE: Nanosystems: Molecular Machinery, Manufacturing, and Computation. John Wiley \& Sons, New York, NY, 1989.

2. Drexler KE: Engines of Creation: The Coming Era of Nanotechnology. Anchor Books, Doubleday, 1986.

3. Belkin A, Hubler A and Bezryadin A: Self-assembled wiggling nano-structures and the principle of maximum entropy production. Sci Rep 5: 8323, 2015.

4. Buzea C, Pacheco II and Robbie K: Nanomaterials and nanoparticles: Sources and toxicity. Biointerphases 2: MR17-MR71, 2007.

5. Kroto HW, Heath O Jr, O'Brien SC, Curl RF and Smalley RE: Buckminsterfullerene. This Week's Citation Classic. Nature 318: 162-163, 1985.

6. Allhoff F, Patrick L and Daniel M: What is Nanotechnology and Why Does it Matter? From Science to Ethics. John Wiley \& Sons, pp3-5, 2010.

7. Mashaghi S, Jadidi T, Koenderink G and Mashaghi A: Lipid nanotechnology. Int J Mol Sci 14: 4242-4282, 2013.

8. Farokhzad OC and Langer R: Nanomedicine: Developing smarter therapeutic and diagnostic modalities. Adv Drug Deliv Rev 58: 1456-1459, 2006.

9. Filipponi L and Nicolau DV: Cell Patterning. Wiley Encyclopedia of Biomedical Engineering. John Wiley \& Sons, 2006.

10. Lombardo D, Kiselev MA and Caccamo MT: Smart Nanoparticles for Drug Delivery Application: Development of Versatile Nanocarrier Platforms in Biotechnology and Nanomedicine. J Nanomater 12: 1-26, 2019.

11. Katsuki S, Matoba T, Koga JI, Nakano K and Egashira K: Anti-inflammatory Nanomedicine for Cardiovascular Disease. Front Cardiovasc Med 4: 87, 2017.

12. Morgan MT, Carnahan MA, Finkelstein S, Prata CA, Degoricija L, Lee SJ and Grinstaff MW: Dendritic supramolecular assemblies for drug delivery. Chem Commun (Camb) 97: 4309-4311, 2005.

13. Tiriveedhi V, Kitchens KM, Nevels KJ, Ghandehari Hand Butko P: Kinetic analysis of the interaction between poly(amidoamine) dendrimers and model lipid membranes. Biochim Biophys Acta 1808: 209-218, 2011.

14. Palmerston Mendes L, Pan J and Torchilin VP: Dendrimers as nanocarriers for nucleic acid and drug delivery in cancer therapy. Molecules 22: 1401, 2017.

15. Kukowska-Latallo JF, Bielinska AU, Johnson J, Spindler R, Tomalia DA and Baker JR Jr: Efficient transfer of genetic material into mammalian cells using Starburst polyamidoamine dendrimers. Proc Natl Acad Sci USA 93: 4897-4902, 1996.

16. Svenson S and Tomalia DA: Dendrimers in biomedical applications - reflections on the field. Adv Drug Deliv Rev 57: 2106-2129, 2005.

17. Nune SK, Gunda P, Thallapally PK, Lin YY, Forrest ML and Berkland CJ: Nanoparticles for biomedical imaging. Expert Opin Drug Deliv 6: 1175-1194, 2009.

18. Shi Kam NW, Jessop TC, Wender PA and Dai H: Nanotube molecular transporters: Internalization of carbon nanotube-protein conjugates into Mammalian cells. J Am Chem Soc 126: 6850-6851, 2004.

19. Pantarotto D, Briand JP, Prato M and Bianco A: Translocation of bioactive peptides across cell membranes by carbon nanotubes. Chem Commun (Camb) 7: 16-17, 2004.

20. Dai HJ, Hafner JH, Rinzler AG, Colbert DT and Smalley RE: Nanotubes as nanoprobes in scanning probe microscopy. Nature 384: 147-150, 1996.

21. Acharya S and Sahoo SK: PLGA nanoparticles containing various anticancer agents and tumour delivery by EPR effect. Adv Drug Deliv Rev 63: 170-183, 2011.

22. Mulder WJ, Strijkers GJ, van Tilborg GA, Cormode DP, Fayad ZA and Nicolay K: Nanoparticulate assemblies of amphiphiles and diagnostically active materials for multimodality imaging. Acc Chem Res 42: 904-914, 2009.

23. Probst CE, Zrazhevskiy P, Bagalkot V and Gao X: Quantum dots as a platform for nanoparticle drug delivery vehicle design. Adv Drug Deliv Rev 65: 703-718, 2013.

24. Medina C, Santos-Martinez MJ, Radomski A, Corrigan OI and Radomski MW: Nanoparticles: Pharmacological and toxicological significance. Br J Pharmacol 150: 552-558, 2007. 
25. Ratner BD and Bryant SJ: Biomaterials: Where we have been and where we are going. Annu Rev Biomed Eng 6: 41-75, 2004.

26. Sakiyama-Elbert SE and Hubbell JA: Functional biomaterials: Design of novel biomaterials. Annu Rev Mater Res 31: 183-201, 2001 .

27. Wickline SA and Lanza GM: Nanotechnology for molecular imaging and targeted therapy. Circulation 107: 1092-1095, 2003.

28. Lanone S and Boczkowski J: Biomedical applications and potential health risks of nanomaterials: Molecular mechanisms. Curr Mol Med 6: 651-663, 2006.

29. Loo C, Lin A, Hirsch L, Lee MH, Barton J, Halas N, West J and Drezek R: Nanoshell-enabled photonics-based imaging and therapy of cancer. Technol Cancer Res Treat 3: 33-40, 2004.

30. Choi MR, Stanton-Maxey KJ, Stanley JK, Levin CS, Bardhan R, Akin D, Badve S, Sturgis J, Robinson JP, Bashir R, et al: A cellular Trojan Horse for delivery of therapeutic nanoparticles into tumors. Nano Lett 7: 3759-3765, 2007.

31. Abbasi A,Park K, Bose A and Bothun GD: Near-Infrared Responsive Gold-Layersome Nanoshells. Langmuir 33: 5321-5327, 2017.

32. Helm L: Optimization of gadolinium-based MRI contrast agents for high magnetic-field applications. Future Med Chem 2: 385-396, 2010

33. Vo-Dinh T and Cullum B: Biosensors and biochips: Advances in biological and medical diagnostics. Fresenius J Anal Chem 366 : 540-551, 2000

34. Silva GA: Neuroscience nanotechnology: Progress, opportunities and challenges. Nat Rev Neurosci 7: 65-74, 2006.

35. Yan Z, Bin Y and Deng YH: Take the initiative to drug-loaded liposomes prepared by vincristine sulfate and the determination of encapsulation efficiency. Chung Kuo Yao Hsueh Tsa Chih 10: $1559,2005$.

36. OchekpeNA,Olorunfemi PO and Ngwuluka NC: Nanotechnology and drug delivery part 1: Background and applications. Trop J Pharm Res 8: 265-274, 2009.

37. Zalipsky S: Polyethylene glycol-lipid conjugates. In: Stealth Liposomes. CRC Press, Boca Raton, pp93-102, 1995.

38. Jain N, Jain R, Thakur N, Gupta BP and Jain DK: Nanotechnology: A Safe and effective drug delivery system. Asian J Pharm Clin Res 3: 159-165, 2010.

39. Kakade T, Kadam V, Dhanavade K and Salunkhe V: A review on pharmaceutical nanotechnology: Dendrimers. World J Pharm Pharm Sci 2: 4815-4830, 2013.

40. Tibbals HF: Medical Nanotechnology and Nanomedicine. CRC Press, Taylor and Francis Group 31, 2011.

41. Siegel R, Naishadham D and Jemal A: Cancer statistics, 2013 CA Cancer J Clin 63: 11-30, 2013.

42. van Vlerken LE, Vyas TK and Amiji MM: Poly(ethylene glycol)-modified nanocarriers for tumor-targeted and intracellular delivery. Pharm Res 24: 1405-1414, 2007.

43. Biswas AK, Islam R, Choudhury ZS, Mostafa A and Kadir MF: Nanotechnology based approaches in cancer therapeutics. Adv Nat Sci Nanosci Nanotechnol 5: 2043-6262, 2004.

44. Gupta P, Vermani K and Garg S: Hydrogels: From controlled release to $\mathrm{pH}$-responsive drug delivery. Drug Discov Today 7: 569-579, 2002

45. Montero AJ, Adams B, Diaz-Montero CM and Glück S: Nab-paclitaxel in the treatment of metastatic breast cancer: A comprehensive review. Expert Rev Clin Pharmacol 4: 329-334, 2011.

46. Tsurutani J,Kuroi K, Iwasa T,Miyazaki M, Nishina S, Makimura C, Tanizaki J, Okamoto K, Yamashita T, Aruga T, et al: Phase study of weekly nab-paclitaxel combined with S-1 in patients with human epidermal growth factor receptor type 2-negative metastatic breast cancer. Cancer Sci 106: 734-739, 2015.

47. McGill HC Jr, McMahan CA and Gidding SS: Preventing heart disease in the 21st century: Implications of the Pathobiological Determinants of Atherosclerosis in Youth (PDAY) study. Circulation 117: 1216-1227, 2008.

48. Das A, Mukherjee P, Singla SK, Guturu P, Frost MC, Mukhopadhyay D, Shah VH and Patra CR: Fabrication and characterization of an inorganic gold and silica nanoparticle mediated drug delivery system for nitric oxide. Nanotechnology 21: 305102, 2010.

49. Deshpande D, Kethireddy S, Janero DR and Amiji MM Therapeutic efficacy of an $\omega-3$-fatty acidcontaining $17-\beta$ estradiol nano-delivery system against experimental atherosclerosis. PLoS One 11: e0147337, 2016

50. Wu T, Chen X, Wang Y, Xiao H, Peng Y, Lin L, Xia W, Long M, Tao J and Shuai X: Aortic plaque-targeted andrographolide delivery with oxidation-sensitive micelle effectively treats atherosclerosis via simultaneous ROS capture and anti-inflammation. Nanomedicine (Lond) 14: 2215-2226, 2018
51. Bulbake U, Doppalapudi S, Kommineni N and Khan W: Liposomal formulations in clinical use: An updated review. Pharmaceutics 9: 12, 2017.

52. Zhang N, Li C, Zhou D, Ding C, Jin Y, Tian Q, Meng X, Pu K and Zhu Y: Cyclic RGD functionalized liposomes encapsulating urokinase for thrombolysis. Acta Biomater 70: 227-236, 2018.

53. Najlah M, Freeman S, Attwood D and D'Emanuele A: In vitro evaluation of dendrimer prodrugs for oral drug delivery. Int $\mathrm{J}$ Pharm 336: 183-190, 2007.

54. Korin N, Gounis MJ, Wakhloo AK and Ingber DE: Targeted drug delivery to flow-obstructed blood vessels using mechanically activated nanotherapeutics. JAMA Neurol 72: 119-122, 2015.

55. Sahaym U and Norton M: Advances in the application of nanotechnology in enabling a hydrogen economy. J Mater Sci 43: 5395-5429, 2008

56. Rickerby DG and Morrison M: Nanotechnology and the environment: A European perspective. Sci Technol Adv Mater 8: 19-24, 2007.

57. Hoshyar N, Gray S, Han H and Bao G: The effect of nanoparticle size on in vivo pharmacokinetics and cellular interaction. Nanomedicine (Lond) 11: 673-692, 2016.

58. Lee JM, Yoon TJ and Cho YS: Recent developments in nanoparticle-based siRNA delivery for cancer therapy. BioMed Res Int 2013: 782041, 2013.

59. Asmatulu R and Asmatulu E: Importance of recycling education: A curriculum development at Wichita State University. J Mater Cycles Waste Manag 14: 1-8, 2011.

60. Narayan RJ, Kumta PN, Sfeir C, Lee DH, Choi D and Olton D: Nanostructured ceramics in medical devices: Applications and prospects. JOM 56: 38-43, 2004.

61. Byrne JD and Baugh JA: The significance of nanoparticles in particle-induced pulmonary fibrosis. Mcgill J Med 11: 43-50, 2008

62. Hubler A and Osuagwu O: Digital quantum batteries: Energy and information storage in nanovacuum tube arrays. Complexity 15 48-55, 2010

63. Shinn E, Hübler A, Lyon D, Perdekamp M, Bezryadin A and Belkin A: Nuclear energy conversion with stacks of graphene nanocapacitors. Complexity 18: 24-27, 2012.

64. Kurtoglu ME, Longenbach T, Reddington P and Gogotsi Y Effect of calcination temperature and environment on photocatalytic and mechanical properties of ultrathin sol-gel titanium dioxide films. J Am Ceram Soc 94: 1101-1108, 2011.

65. Prencipe G, Tabakman SM, Welsher K, Liu Z, Goodwin AP, Zhang L, Henry J and Dai H: PEG branched polymer for functionalization of nanomaterials with ultralong blood circulation. J Am Chem Soc 131: 4783-4787, 2009.

66. Swanson SD, Kukowska-Latallo JF, Patri AK, Chen C, Ge S, Cao Z Kotlyar A, East AT and Baker JR: Targeted gadolinium-loaded dendrimer nanoparticles for tumor-specific magnetic resonance contrast enhancement. Int J Nanomedicine 3: 201-210, 2008

67. Waters EA and Wickline SA: Contrast agents for MRI. Basic Res Cardiol 103: 114-121, 2008

68. Smith AM, Duan H, Mohs AM and Nie S: Bioconjugated quantum dots for in vivo molecular and cellular imaging. Adv Drug Deliv Rev 60: 1226-1240, 2008

69. Wunderbaldinger P, Josephson L, Bremer C, Moore A and Weissleder R: Detection of lymph node metastases by contrast-enhanced MRI in an experimental model. Magn Reson Med 47: 292-297, 2002

70. Thorek DL and Tsourkas A: Size, charge and concentration dependent uptake of iron oxide particles by non-phagocytic cells. Biomaterials 29: 3583-3590, 2008

71. Nie L, Liu F, Ma P and Xiao X: Applications of gold nanoparticles in optical biosensors. J Biomed Nanotechnol 10: 2700-2721, 2014

72. Daraee H, Eatemadi A, Abbasi E, Fekri Aval S, Kouhi M and Akbarzadeh A: Application of gold nanoparticles in biomedical and drug delivery. Artif Cells Nanomed Biotechnol 44: 410-422, 2016.

73. Cole LE, Ross RD, Tilley JM, Vargo-Gogola T and Roeder RK Gold nanoparticles as contrast agents in x-ray imaging and computed tomography. Nanomedicine (Lond) 10: 321-341, 2015.

74. Hwang S, Nam J, Jung S, Song J, Doh H and Kim S: Gold nanoparticle-mediated photothermal therapy: Current status and future perspective. Nanomedicine (Lond) 9: 2003-2022, 2014.

75. Park JA, Lee JJ, Jung JC, Yu DY, Oh C, Ha S, Kim TJ and Chang Y: Gd-DOTA conjugate of RGD as a potential tumor-targeting MRI contrast agent. ChemBioChem 9: 2811-2813, 2008

76. Zhang W, Yong D, Huang J, Yu J, Liu S and Fan MX: Fabrication of polymer-gadolinium (III) complex nanomicelle from poly(ethylene glycol)-polysuccinimide conjugate and diethylenetriaminetetraacetic acid-gadolinium as magnetic resonance imaging contrast agents. J Appl Polym Sci 120: 2596-2605, 2011. 
77. Karfeld-Sulzer LS, Waters EA, Davis NE, Meade TJ and Barron AE: Multivalent protein polymer MRI contrast agents: Controlling relaxivity via modulation of amino acid sequence. Biomacromolecules 11: 1429-1436, 2010.

78. Kamaly N and Miller AD: Paramagnetic liposome nanoparticles for cellular and tumour imaging. Int J Mol Sci 11: 1759-1776, 2010.

79. Na HB, Song IC and Hyeon T: Inorganic Nanoparticles for MRI Contrast Agents. Adv Mater 21: 2133-2148, 2019.

80. Shao YZ, Liu LZ, Song SQ, Cao RH, Liu H, Cui CY, Li X, Bie MJ and Li L: A novel one-step synthesis of $\mathrm{Gd}^{+}$-incorporated mesoporous $\mathrm{SiO}_{2}$ nanoparticles for use as an efficient MRI contrast agent. Contrast Media Mol Imaging 6: 110-118, 2011.

81. Bobo D, Robinson KJ, Islam J, Thurecht KJ and Corrie SR: Nanoparticle-based medicines: A review of FDA-approved materials and clinical trials to date. Pharm Res 33: 2373-2387, 2016

82. Qiao R, Yang C and Gao M: Superparamagnetic iron oxide nanoparticles: From preparations to in vivo MRI applications. J Mater Chem 19: 6274-6293, 2009.

83. Teja AS and Koh P: Synthesis, properties, and applications of magnetic iron oxide nanoparticles. Prog Cryst Growth Charact Mater 55: 22-45, 2009.

84. Murbe J, Rechtenbach A and Topfer J: Synthesis and physical characterisation of magnetite nanoparticles for biomedical applications. Mater Chem Phys 110: 426-433, 2008

85. Sun C, Lee JS and Zhang M: Magnetic nanoparticles in MR imaging and drug delivery. Adv Drug Deliv Rev 60: 1252-1265, 2008

86. Hong J, Gong P, Xu D, Sun H and Yao S: Synthesis and characterisation of carboxyl functionalised magnetic nanogel via 'green' photochemical method. J Appl Polym Sci 105: 1882-1887, 2007.

87. Gupta AK and Gupta M: Synthesis and surface engineering of iron oxide nanoparticles for biomedical applications. Biomaterials 26: 3995-4021, 2005.

88. Rabin O, Manuel Perez J, Grimm J, Wojtkiewicz G and Weissleder R: An X-ray computed tomography imaging agent based on long-circulating bismuth sulphide nanoparticles. Nat Mater 5: 118-122, 2006.

89. Hahn MA, Singh AK, Sharma P, Brown SC and Moudgil BM: Nanoparticles as contrast agents for in-vivo bioimaging: Current status and future perspectives. Anal Bioanal Chem 399: 3-27, 2011.

90. Elrod DB, Partha R, Danila D, Casscells SW and Conyers JL: An iodinated liposomal computed tomographic contrast agent prepared from a diiodophosphatidylcholine lipid. Nanomedicine (Lond) 5: 42-45, 2009.

91. Kweon S, Lee HJ, Hyung WJ, Suh J, Lim JS and Lim SJ: Liposomes coloaded with iopamidol/lipiodol as a RES-targeted contrast agent for computed tomography imaging. Pharm Res 27: 1408-1415, 2010

92. Zheng J, Allen C, Serra S, Vines D, Charron M and Jaffray DA Liposome contrast agent for CT-based detection and localization of neoplastic and inflammatory lesions in rabbits: Validation with FDG-PET and histology. Contrast Media Mol Imaging 5: $147-154,2010$
93. Chrastina A and Schnitzer JE: Iodine-125 radiolabeling of silver nanoparticles for in vivo SPECT imaging. Int J Nanomedicine 5 653-659, 2010.

94. Van Herck JL, De Meyer GR, Martinet W, Salgado RA, Shivalkar B, De Mondt R, Van De Ven H, Ludwig A, Van Der Veken P, Van Vaeck L, et al: Multi-slice computed tomography with N1177 identifies ruptured atherosclerotic plaques in rabbits. Basic Res Cardiol 105: 51-59, 2010

95. Aillon KL, El-Gendy N, Dennis C, Norenberg JP, McDonald J and Berkland C: Iodinated NanoClusters as an inhaled computed tomography contrast agent for lung visualization. Mol Pharm 7: 1274-1282, 2010.

96. Hainfeld JF, Slatkin DN, Focella TM and Smilowitz HM: Gold nanoparticles: A new X-ray contrast agent. Br J Radiol 79: 248-253, 2006.

97. Kim D, Park S, Lee JH, Jeong YY and Jon S: Antibiofouling polymer-coated gold nanoparticles as a contrast agent for in vivo X-ray computed tomography imaging. J Am Chem Soc 129: 7661-7665, 2007.

98. Pan J, Wang Y and Feng SS: Formulation, characterization, and in vitro evaluation of quantum dots loaded in poly(lactide)-vitamin $\mathrm{E}$ TPGS nanoparticles for cellular and molecular imaging. Biotechnol Bioeng 101: 622-633, 2008.

99. Yang L, Mao H, Wang YA, Cao Z, Peng X, Wang X, Duan H, Ni C, Yuan Q, Adams G, et al: Single chain epidermal growth factor receptor antibody conjugated nanoparticles for in vivo tumor targeting and imaging. Small 5: 235-243, 2009.

100. Ballou B, Ernst LA and Waggoner AS: Fluorescence imaging of tumors in vivo. Curr Med Chem 12: 795-805, 2005.

101. Ballou B, Ernst LA, Andreko S, Harper T, Fitzpatrick JA, Waggoner AS and Bruchez MP: Sentinel lymph node imaging using quantum dots in mouse tumor models. Bioconjug Chem 18: 389-396, 2007

102. Serp P, Corrias M and Kalck P: Carbon nanotubes and nanofibers in catalysis. Appl Catal 253: 337-358, 2003

103. Ghosh M, Singh AT, Xu W, Sulchek T, Gordon LI and Ryan RO: Curcumin nanodisks: Formulation and characterization. Nanomedicine (Lond) 7: 162-167, 2011.

104. Singh P: Impacts of nanotechnology on environmental (Review). Int Arch App Sci Technol 9: 14-16, 2018.

105. Chandarana M, Curtis A and Hoskins C: The use of nanotechnology in cardiovascular disease. Appl Nanosci 8: 1607-1619, 2018

106. Dreher KL: Health and environmental impact of nanotechnology: Toxicological assessment of manufactured nanoparticles. Toxicol Sci 77: 3-5, 2004.

107. Lam CW, James JT, McCluskey R and Hunter RL: Pulmonary toxicity of single-wall carbon nanotubes in mice 7 and 90 days after intratracheal instillation. Toxicol Sci 77: 126-134, 2004.

108. Stander L and Theodore L: Environmental implications of nanotechnology - an update. Int J Environ Res Public Health 8: 470-479, 2011.

109. Babatunde D, Denwigwe IH, Babatunde OM, Gbadamosi SL, Babalola IP and Agboola O: Environmental and Societal Impact of Nanotechnology. IEEE Access 8: 4640-4667, 2020. 